\title{
Trends in Age and Anthropometric Data at Start of Growth Hormone Treatment for Girls with Turner Syndrome in Japan
}

\author{
TSUYOSHI ISOJIMA*, SUSUMU YOKOYA*,**, JUNKO ITO**,***, REIKO HORIKAWA*,*** \\ AND TOSHIAKI TANAKA***,\# \\ *Clinical Research Center, National Center for Child Health and Development, 2-10-1 Ohkura, Setagaya-ku, Tokyo, 157-8535, \\ Japan \\ **Toranomon Hospital, 2-2-2 Toranomon, Minato-ku, Tokyo, 105-8470, Japan \\ ***The Foundation for Growth Science, Japan, 5-1-16 Hongo, Bunkyo-ku, Tokyo, 113-0033, Japan \\ \#Tanaka Growth Clinic, 1-12-39 Taishidoh, Setagaya-ku, Tokyo, 154-0004, Japan
}

\begin{abstract}
The purpose of this study is to evaluate the trends in age and anthropometric data for girls with Turner syndrome (TS) at start of growth hormone (GH) treatment in Japan. The data for analysis were obtained from a retrospective cohort, the Foundation for Growth Science, Japan. We analyzed trends in starting age of GH treatment for girls with TS in Japan after dividing subjects $(\mathrm{n}=1,478)$ into three registration periods: $1991-1994,1995-1999$ and 20002004. We also assessed the ratio of the subpopulation of subjects under five years of age. As results, the mean age (standard deviation (SD)) at start of GH treatment was significantly different among the three groups (10.95 (3.63), 10.15 (3.39) and $8.78(3.61), \mathrm{p}<0.0001)$. The proportion of the subjects under five years of age increased significantly over time $(5.11 \%, 7.11 \%$ and $16.85 \%, \mathrm{p}<0.0001)$. Mean (SD) height SD scores were also significantly different $(-3.41(0.87),-3.26$ $(0.81)$ and $-3.17(0.79), p<0.0001)$. However, the proportions of the karyotype of $45, \mathrm{X}$ were not significantly different among the three groups $(\mathrm{p}=0.25)$. We concluded that age and shortness at initiation of $\mathrm{GH}$ treatment had been improving over time. However, these favorable trends have not fully met the conditions recommended by international clinical guidelines for TS.
\end{abstract}

Key words: Turner syndrome, Growth hormone, Growth failure, Diagnosis delay

(Endocrine Journal 55: 1065-1070, 2008)

TURNER syndrome (TS) is caused by a complete or partial absence of the second sex chromosome, and affects one in 2,000 to 5,000 live-born females [1]. One of the most significant features of the syndrome is short stature. Untreated adults are reported to be approximately $20 \mathrm{~cm}$ shorter than normal females within their respective populations [2]. Growth hormone $(\mathrm{GH})$ has been used to accelerate growth, and has been known to increase adult height [3]. GH is usually in-

Received: May 14, 2008

Accepted: August 7, 2008

Correspondence to: Tsuyoshi ISOJIMA, Clinical Research Center, National Center for Child Health and Development, 2-101 Ohkura, Setagaya-ku, Tokyo, 157-8535, Japan

Abbreviations TS: Turner syndrome, GH: Growth hormone, SDS: Standard deviation score, ANOVA: Analysis of variance troduced after a child's height falls below the fifth percentile for normal girls of the same age [4]. Though the optimal age for initiation of GH treatment has not been established [5], it is preferable not to start GH treatment later than five years of age, because the height of the majority of girls with TS usually drops below the fifth percentile of the normal girl growth curve between two and five years of age [1]. Many studies on GH treatment in girls with TS have established the importance of age at treatment initiation for long-term height gain [6-14]. Moreover, a recent study has shown that early GH treatment could normalize height in infants and toddlers with TS, and restoration of height close to the average would mitigate the potential detrimental effects of short stature during childhood and allow for age-appropriate initiation of feminization [15]. In Western countries, the age at ini- 
tiation of GH treatment has become younger [16, 17], although many patients with TS are left undiagnosed until mid-childhood, adolescence or even adulthood [17-20].

In Japan, GH treatment for girls with TS was approved by the Ministry of Health and Welfare in 1991 only for those accompanying GH deficiency with short stature below -2 standard deviation score (SDS), and in 1999 for all girls whose height was below -2 SDS. As in other countries, we speculate that the initiation age of GH treatment appears to have become younger, and medical doctors feel that the degree of growth failure at the start of $\mathrm{GH}$ treatment has become less severe. However, no reports have verified this speculation with large cohort study data. In this study we evaluated the trends in age and anthropometric data of girls with TS in Japan at initiation of GH treatment using data collected at the Foundation for the Growth Science, Japan [21].

\section{Subjects and Methods}

\section{Subjects}

The subjects were obtained from a retrospective cohort, the Foundation for Growth Science, which has been controlling the use of GH through its registration system. The Foundation evaluates the candidate's eligibility for GH treatment according to certain diagnostic criteria for GH deficiency, TS and other pertinent disorders [21]. Physicians are encouraged to register each candidate for GH treatment at the Foundation using an application form which includes the candidate's pre-treatment anthropometric measurements, karyotypes (in the case of TS), presence or absence of puberty, and evidence of informed consent from each subject regarding the use of the data for scientific purposes.

Between 1991 and 2004, 1,867 girls were registered as TS subjects in this cohort, and 1,760 girls were judged to be eligible for GH treatment. These subjects comprise approximately two-thirds of all TS girls treated with GH in Japan, judging from the data compiled in medical aid programs for chronic pediatric diseases of specified categories in Japan [22, 23]. Although subjects with TS shorter than -2 SDS were approved for GH treatment in Japan, 24 subjects above -2 SDS were judged to be eligible on an individual basis. The diagnosis of TS was confirmed by reviewing all the reported karyotypes of cultured peripheral blood lymphocytes. In this study TS was defined as a karyotype which contains a monosomic cell line lacking at least a major portion of the distal part in the short arm of the X chromosome. Subjects having no evidence of such karyotypic features, or with a history of previous growth-promoting therapy such as $\mathrm{GH}$ or anabolic steroids or both were excluded. Two reasons are listed as to why GH treatment was introduced before registration: the first is that some subjects had participated in clinical studies for the governmental approval; the second is that some subjects had initially been treated for GH deficiency, and then reregistered with the Foundation after diagnosis of TS. In this study, we excluded all these subjects with prior growthpromoting therapy, because our aim was to study trends not only of age of GH initiation but also of the degree of growth retardation at start of GH treatment as girls with TS.

\section{Methods}

First of all, all subjects were analyzed for the difference between karyotypes of $45, X$ and non- $45, X$. In Belgium, a negative correlation was detected between age at diagnosis and height SDS for the normal population, which suggested delayed diagnosis of TS [24]. As our retrospective cohort did not contain ages at initial diagnosis, we studied the correlations between age at initiation of GH treatment (instead of age at initial diagnosis) and height SDS for the normal population or TS-specific population.

Many girls with TS who had been diagnosed well before the start of the study period appeared to have been registered in the first two years after the start of registration (1991), but registration numbers went down to relatively constant figures in the following two years. Thereafter, all the girls with TS shorter than -2 SDS irrespective of GH secretion status became eligible for GH treatment in November 1999. The subjects were therefore divided into three registration periods: 1991-1994, 1995-1999 and 2000-2004. We also analyzed the subpopulation of subjects under five years of age in each period to clarify the trend toward younger ages. 


\section{Statistical analysis}

The results are expressed as the mean (SD), or by frequency and percent. Ages are also expressed as the median. Height SDS, TS-specific height SDS and body mass index (BMI) SDS were calculated by comparison with the Japanese 1990 growth reference [25], the currently used Japanese TS growth chart [26], and the Japanese BMI-for-age chart [27], respectively.

Comparisons of groups were assessed by one-way analysis of variance (ANOVA) or unpaired t-test for numeric variables, and chi-square test for categorical variables. When the result was significant, the differences between groups were subjected to two-by-two comparisons with post-hoc Bonferroni correction for multiple comparisons. Correlations were performed by Pearson's test. All analyses were made using JMP 6.0.3 (SAS Institute Inc., Cary, NC, USA) and P values less than 0.05 were considered statistically significant.

\section{Results}

In total, 282 subjects were excluded because of insufficient or inadequate cytogenetic basis of the diagnosis (24 subjects), previous growth-promoting treatment (255 subjects), and highly unlikely measurements ( 3 subjects). In the total of 255 subjects with previous growth-promoting treatment, the subjects in the three periods (i.e. 1991-1994, 1995-1999 and 2000-2004) are 163, 61 and 31 subjects, respectively. There were 217 subjects $(85.1 \%)$ who had been treated with GH. The remaining 1,478 subjects formed the cohort of analysis. In the analysis of all subjects, neither age nor anthropometric indices were significantly different between 45,X and non-45, X subjects (Table 1). There was a strong negative correlation between age at initiation of GH treatment and height SDS for the normal population $(\mathrm{r}=-0.36, \mathrm{p}<0.0001)$ (Fig. 1), and a strong positive correlation between age and TSspecific height SDS $(r=0.36, p<0.0001)$ (Fig. 2).

Table 2 summarizes the characteristics of girls with TS at initiation of GH treatment grouped by registration years. Mean ages (SD) in the three periods (i.e. 1991-1994, 1995-1999 and 2000-2004) were significantly different (10.95 (3.63), 10.15 (3.39) and 8.78 (3.61), $\mathrm{p}<0.0001)$. Means of height SDS for normal girls were also significantly different $(-3.41(0.87)$,
Table 1. Characteristics of girls with TS at initiation of GH treatment according to karyotype

\begin{tabular}{lccc}
\hline & $\begin{array}{c}45, \mathrm{X} \\
(\mathrm{n}=422)\end{array}$ & $\begin{array}{c}\text { non-45,X } \\
(\mathrm{n}=1,056)\end{array}$ & P value \\
\hline Age (year) & $\begin{array}{c}10.07(3.68) \\
\text { median: } 10.25\end{array}$ & $\begin{array}{c}10.22(3.65) \\
\text { median: } 10.42\end{array}$ & 0.46 \\
Height SDS & $-3.26(0.87)$ & $-3.32(0.82)$ & 0.17 \\
TS Height SDS & $0.35(1.00)$ & $0.30(0.91)$ & 0.36 \\
BMI SDS & $0.70(1.15)$ & $0.64(1.22)$ & 0.36 \\
\hline
\end{tabular}

All the data are expressed as means (SD) unless otherwise indicated. $\mathrm{P}$ values refer to differences between groups as determined by unpaired $t$ test. Height SDS indicates height SDS for normal girls; TS Height SDS, height SDS for girls with TS.

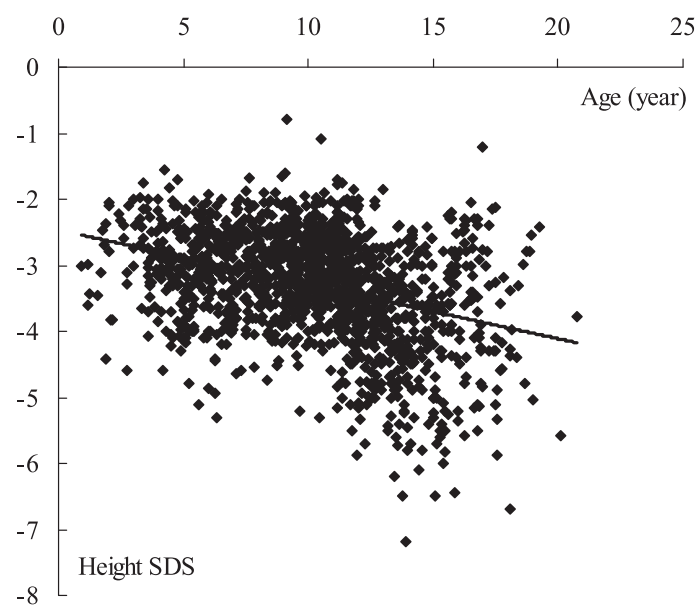

Fig. 1. Correlation between age at registration for GH treatment and height SDS for the normal population [25] $(\mathrm{r}=-0.36, \mathrm{p}<0.0001)$. Although girls with TS shorter than -2 SDS receive approval for GH treatment in Japan, exceptional subjects above -2 SDS are judged eligible on an individual basis.

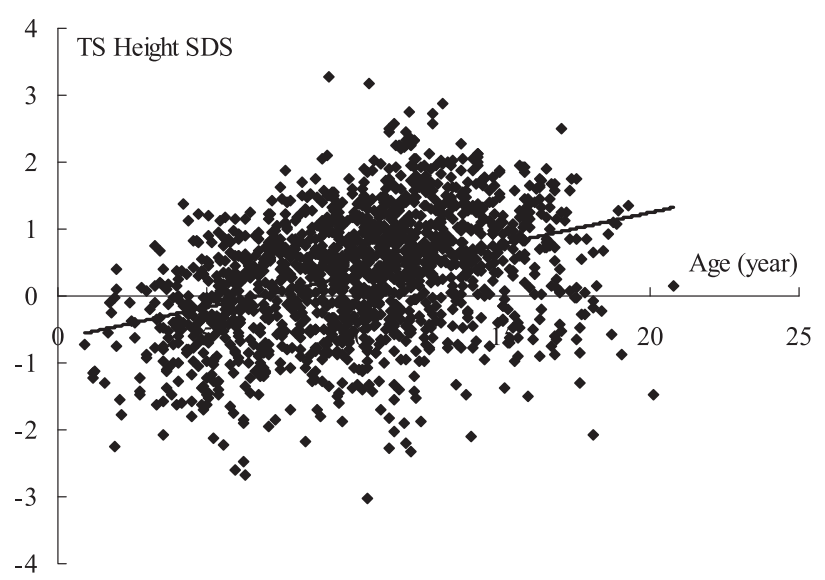

Fig. 2. Correlation between age at registration for $\mathrm{GH}$ treatment and height SDS for TS [26] $(r=0.36, p<0.0001)$. 
Table 2. Characteristics of girls with Turner syndrome at initiation of GH treatment grouped by registration years

\begin{tabular}{|c|c|c|c|c|c|}
\hline & $\begin{array}{c}1991-1994 \\
(\mathrm{n}=665)\end{array}$ & $\begin{array}{c}1995-1999 \\
(\mathrm{n}=451)\end{array}$ & $\begin{array}{c}2000-2004 \\
(\mathrm{n}=362)\end{array}$ & $\begin{array}{c}\text { Total } \\
(\mathrm{n}=1,478)\end{array}$ & $P$ value \\
\hline 45,X karyotype & $204(30.68 \%)$ & $123(27.27 \%)$ & $95(26.24 \%)$ & $422(28.55 \%)$ & 0.25 \\
\hline Age (year) & $\begin{array}{c}10.95(3.63) \\
\text { median: } 11\end{array}$ & $\begin{array}{l}10.15(3.39)^{(a)} \\
\text { median: } 10.33\end{array}$ & $\begin{array}{l}8.78(3.61)^{(\mathfrak{b}, \mathrm{c})} \\
\text { median: } 8.79\end{array}$ & $\begin{array}{c}10.18(3.66) \\
\text { median: } 10.33\end{array}$ & $<0.0001$ \\
\hline Subjects under five years of age & $34(5.11 \%)$ & $32(7.11 \%)$ & $61(16.85 \%)^{(b, c)}$ & $127(8.59 \%)$ & $<0.0001$ \\
\hline Height SDS & $-3.41(0.87)$ & $-3.26(0.81)^{\left(\mathrm{a}^{\prime}\right)}$ & $-3.17(0.79)^{(b)}$ & $-3.30(0.84)$ & $<0.0001$ \\
\hline TS height SDS & $0.34(0.91)$ & $0.37(0.92)$ & $0.21(1.00)$ & $0.32(0.94)$ & 0.032 \\
\hline BMI SDS & $0.69(1.20)$ & $0.72(1.18)$ & $0.51(1.21)^{\left(c^{\prime}\right)}$ & $0.65(1.20)$ & 0.023 \\
\hline
\end{tabular}

$\mathrm{P}$ values refer to differences between groups as determined by ANOVA and chi-square test for numeric variables and categorical variables, respectively.

$\mathrm{a}: \mathrm{p}=0.0002$ for $1991-1994$ vs 1995-1999, $\mathrm{a}^{\prime}: \mathrm{p}=0.00027$ for 1991-1994 vs 1995-1999, $\mathrm{b} ; \mathrm{p}<0.0001$ for 1991-1994 vs 2000-2004, c; $\mathrm{p}<0.0001$ for $1995-1999$ vs 2000-2004, c'; $\mathrm{p}=0.010$ for 1995-1999 vs 2000-2004.

$-3.26(0.81)$ and $-3.17(0.79), \mathrm{p}<0.0001)$. However, the proportions of the karyotype of $45, \mathrm{X}$ in the three groups were not significantly different $(\mathrm{p}=0.25)$. Post-hoc analysis between 1991-1994 and 2000-2004 revealed that the average age decreased significantly $(\mathrm{p}<0.0001)$, and that the height SDS for normal girls increased significantly $(p<0.0001)$. Average age was also significantly different between subjects in 19951999 and those in 2000-2004 ( $<<0.0001)$, but height SDS for normal girls did not change significantly between the two groups $(p=0.12)$. Among all the 1,478 subjects, the number of subjects under five years of age was $127(8.59 \%)$. The proportion in each group changed significantly by registration year group $(5.11 \%, 7.11 \%$ and $16.85 \%, \mathrm{p}<0.0001)$, and post-hoc analysis showed a significant increase in the proportion of subjects under five years of age $(p<0.0001)$ (Table 2). When we performed the same analysis with 1,733 subjects including previous growth-promoting treatment, we obtained the same trends as the results from 1,478 subjects (data not shown).

\section{Discussions}

The age of girls with TS at initiation of GH treatment has been getting younger in Japan as evidenced by this retrospective large cohort (Table 2). Moreover, the proportion of subjects under five years of age has grown significantly over time. These trends are favorable for the better management of girls with TS. These desirable trends have also been observed in Western countries. From the Pharmacia and Upjohn Interna- tional Database (KIGS) in the UK [16], the mean age of starting GH treatment has reduced from 10.4 in 1986 to 8.5 in 1996. The database of the Belgian Study Group for Pediatric Endocrinology [17] revealed that the median age at diagnosis was 11.2 years of age in 1991 and 6.6 in 2003. Taking both foreign and Japanese trends together, the age of GH initiation in Japan has come closer to that in Western countries.

We found a negative correlation between age and height SDS for the normal population (Fig. 1). This finding is conceivable, because girls with TS generally tend to lose height SDS as they grow. However, we also found a positive correlation between age and TSspecific height SDS (Fig. 2), suggesting that relatively small girls in the TS population tended to undergo GH earlier, and that relatively tall ones often suffered from short stature for many years before GH treatment. Regarding height SDS, it has been improving significantly when we compare subjects in 1991-1994 with those in 2000-2004. We do not think this improvement is not due to the character of the subjects on their GH secretion status. Girls with TS generally have a normal GH secretory pattern [3, 5], and their height does not differ irrespective of their GH secretory status [28]. Height SDS for the normal population was not significantly different between subjects in 1995-1999 and those in 2000-2004. Judging from the fact that mean height SDS at initiation in the most recent group (2000-2004) was $-3.30(0.84)$ in all subjects, and $-2.98(0.65)$ in subjects under five years of age, the majority of girls with TS initiated GH treatment only after their growth retardation had become serious. The most recent clinical practice guideline issued by the 
Turner Syndrome Consensus Study Group recommends that the goal of growth-promoting therapies should be to attain normal height as early as possible, and that the diagnosis of TS should be considered in any female with unexplained growth failure or pubertal delay or any other stigmata such as edema of the hands or feet, nuchal fold, or left-sided cardiac anomalies [5]. Therefore, we have to conclude that the present situation in Japan concerning GH treatment for girls with TS is still not satisfactory for their optimal care.

In this study, no difference was detected in ages or all the anthropometric indices between $45, \mathrm{X}$ and non45,X karyotypes (Table 1). This finding was the same in the subgroup limited to subjects under five years of age (data not shown). According to reports from countries other than Japan, girls with 45, X karyotype are usually diagnosed earlier than girls with non- $45, X$ karyotype because of their more typical and severe clinical manifestations $[17-19,29,30]$. One possible explanation is that diagnosis at infancy is not very common in Japan. However, further study is needed to uncover whether diagnosis delay exists in Japan, because this retrospective cohort study was not designed for epidemiological investigation and did not contain ages at initial diagnosis.

In conclusion, the age of girls with TS at initiation of GH treatment has been getting younger, and the proportion of subjects receiving GH treatment under five years of age has grown significantly. However, despite these favorable trends the situation of $\mathrm{GH}$ treatment for girls with TS in Japan has not reached the optimal levels recommended in clinical guidelines issued by the Turner Syndrome Consensus Study Group.

\section{Acknowledgement}

We wish to thank all the registered patients and physicians involved in this retrospective cohort. This study was partly supported by a grant from the Foundation for Growth Science, Japan.

\section{References}

1. Saenger P (1996) Turner's syndrome. $N$ Engl J Med 335: 1749-1754.

2. Ranke MB, Grauer ML (1993) Adult height in Turner syndrome: results of multinational survey 1993. Horm Res 42: 90-94.

3. Baxter L, Bryant J, Cave CB, Milne R (2007) Recombinant growth hormone for children and adolescents with Turner syndrome. Cochrane Database Syst Rev Jan 24; (1): CD003887. Review.

4. Frías JL, Davenport ML, Committee on Genetics and Section on Endocrinology (2003) Health supervision for children with Turner syndrome. Pediatrics 111: 692-702.

5. Bondy CA for The Turner Syndrome Consensus Study Group (2007) Care of girls and women with Turner syndrome: a guideline of the Turner syndrome study group. J Clin Endocrinol Metab 92: 10-25.

6. Quigley CA, Crowe BJ, Anglin DG, Chipman JJ, The U.S. Turner syndrome study group (2002) Growth hormone and low dose estrogen in Turner syndrome: results of a United States multi-center trial to near-final height. J Clin Endocrinol Metab 87: 2033-2041.

7. Van Pareren YK, de Muinck Keizer-Schrama SM, Stijnen T, Sas TCJ, Jansen M, Otten BJ, HoorwegNijman JJG, Vulsma T, Stokvis-Brantsma WH, Rouwé $\mathrm{CW}$, Reeser HM, Gerver WJ, Gosen JJ, Rongen-
Westerlaken C, Drop SLS (2003) Final height in girls with Turner syndrome after long-term growth hormone treatment in three dosages and low dose estrogens. $J$ Clin Endocrinol Metab 88: 1119-1125.

8. Canadian Growth Hormone Advisory Committee (2005) Impact of growth hormone supplementation on adult height in Turner syndrome: results of the Canadean randomized control trial. J Clin Endocrinol Metab 90: 3360-3366.

9. Ranke MB, Partsch CJ, Lindberg A, Dörr HG, Bettendori M, Hauffa BP, Schwarz HP, Mehls O, Sander S, Stahnke N, Steinkamp H, Said E, Sippell W (2002) Adult height after GH therapy in 188 UllrichTurner syndrome patients: results of the German IGLU Follow-Up Study 2001. Eur J Endocrinol 147: 625633.

10. Pasquino AM, Pucarelli I, Segni M, Tarani L, Calcaterra V, Larrizza D (2005) Adult height in sixty girls with Turner syndrome treated with growth hormone matched with an untreated group. $J$ Endocrinol Invest 28: $350-356$.

11. Soriano-Guillen L, Coste J, Ecosse E, Léger J, Tauber M, Cabrol S, Nicolino M, Brauner R, the StaTur Study Group, Chaussain JL, Carel JC (2005) Adult height and pubertal growth in Turner syndrome after treatment with recombinant growth hormone. J Clin Endocrinol 
Metab 90: 5197-5204.

12. Reiter EO, Blethen SL, Baptista J, Price L. (2001) Early initiation of growth hormone treatment allows age-appropriate estrogen use in Turner's syndrome. $J$ Clin Endocrinol Metab 86: 1936-1941.

13. Wasniewsla M, De Luca F, Bergamaschi R, Guarneri MP, Mazzanti L, Matarazzo P, Petri A, Crisafulli G, Salzano G, Lombardo F (2004) Early treatment with $\mathrm{GH}$ alone in Turner syndrome: prepubertal catch-up growth and waning effect. Eur J Endocrinol 151: 567572.

14. Ranke MB, Lindberg A, Longás AF, Darendellier F, Albertsson-Wikland K, Dunger D, Cutfield WS, Tauber M, Wilton P, Wollmann HA, Reiter EO (2007) Major determinants of height development in Turner syndrome (TS) patients treated with GH: analysis of 987 patients from KIGS. Pediatr Res 67: 105-110.

15. Davenport ML, Crowe BJ, Travers SH, Rubin K, Ross JL, Fechner PY, Gunther DF, Liu C, Geffner ME, Thrailkill K, Huseman C, Zagar AJ, Quigley CA (2007) Growth hormone treatment of early growth failure in toddlers with Turner syndrome: a randomized, controlled, multicenter trial. J Clin Endocrinol Metab 92: 3406-3416.

16. Betts PR, Butler GE, Donaldson MDC, Dunger DB, Johonston DI, Kelnar CJH, Krik J, Price DA, Wilton P (1999) A decade of growth hormone treatment in girls with Turner syndrome in the UK. UK KIGS Executive Group. Arch Dis Child 80: 221-225.

17. Massa G, Verlinde F, De Schepper J, Thomas M, Bourguignon JP, Craen M, de Zegher F, Francois I, Du Caju M, Maes M, Heinrichs C; the Belgian Study Group for Paediatric Endocrinology (2005) Trends in age at diagnosis of Turner syndrome. Arch Dis Child 90: 267-268.

18. Gravholt CH (2004) Epidemiological, endocrine and metabolic features in Turner syndrome. Eur J Endocrinol 151: 657-687.

19. Sävendahl L, Davenport ML (2000) Delayed diagnoses of Turner's syndrome: proposed guidelines for change. J Pediatr 137: 455-459.

20. Sybert VP, McCauley E (2004) Turner's syndrome. $N$
Engl J Med 351: 1227-1238.

21. Tanaka T, Takano K, Hanew K, Nishi Y, Igarashi Y, Hirano T, Saito T, Tachibana K, Yokoya S, Fujieda K, Shimatsu A, Hizuka N, Tsushima T, Irie M (1998) Registration system for growth hormone $(\mathrm{GH})$ treatment with standardized immunoreactive $\mathrm{GH}$ values in Japan. Endocr J 45: 459-465.

22. Gu YH, Kato T, Harada S, Sato Y, Kakee N (2008) Medical aid program for chronic pediatric diseases of specified categories in Japan: Current status and future prospects. Pediatr Int 50: 376-387.

23. Fujieda K (2004) Medical aid program for chronic pediatric disease of specified categories in Japan available online at: http: //www.pediatric-world.com/ asahikawa/2007symaken/index.html Accessed June 23, 2008.

24. Massa G, Vanderschueren-Lodeweyckx M (1991) Age and height at diagnosis in Turner syndrome: influence of parental height. Pediatrics 88: 1148-1152.

25. Suwa S, Tachibana K (1993) Standard growth charts for height and weight of Japanese children from birth to 17 years based on a cross-sectional survey of national data. Clin Pediatr Endocrinol 2: 87-97.

26. Suwa $S$ (1992) Standards for growth and growth velocity in Turner's syndrome. Acta Paediatr Jpn 34: 206221.

27. Inokuchi M, Hasegawa T, Anzo M, Matsuo N (2006) Standardized centile curves of body mass index for Japanese children and adolescents based on the 19781981 national survey date. Ann Hum Biol 33: 444-453.

28. Tanaka T, Hibi I, Shizume K (1991) GH-secretion capacity in Turner syndrome and its relations to clinical characteristics and effect of GH treatment - a comparison with pituitary dwarfism-. Folia Endocrinol 67: 597-610 [in Japanese].

29. Stochholm K, Juul S, Juel K, Naeraa RW, Gravholt CH (2006) Prevalence, incidence, diagnostic delay, and mortality in Turner syndrome. J Clin Endocrinol Metab 91: 3897-3902.

30. Ostberg JE, Conway GS (2003) Adulthood in women with Turner syndrome. Horm Res 59: 211-221. 